\title{
Circle time for social and emotional learning in primary school
}

\author{
Carmel Cefai $^{\mathrm{a} *}$, Erika Ferrario ${ }^{\mathrm{b}}$, Valeria Cavioni ${ }^{\mathrm{c}}$, Audrey Carter ${ }^{\mathrm{d}}$ and Tracy Grech ${ }^{\mathrm{d}}$ \\ ${ }^{a}$ University of Malta, Malta; ${ }^{b}$ University of Bicocca, Italy; ${ }^{c}$ University of Pavia, Italy; ${ }^{d}$ Education \\ Directorate, Malta
}

(Received 19 August 2013; final version received 9 October 2013)

\begin{abstract}
This paper discusses the findings and implications of a semi-randomised control trial study on the effectiveness of circle time (CT) on primary school students' social and emotional learning, as well as classroom teachers' and students' experience of CT. A social and emotional learning programme was delivered through CT by trained classroom teachers across the years in one primary school, with other classrooms serving as control groups. The classroom teachers completed the Strengths and Difficulties Questionnaire (SDQ) at pre- and post-intervention, while the CT teachers also completed a questionnaire on their experience of implementing CT in the classroom. The CT students also completed a questionnaire on their own experience of CT. The SDQ scores suggest that $\mathrm{CT}$ students showed less internalised difficulties when compared to their control peers, while the qualitative data from both teachers and students suggest that the CT students also exhibited less behaviour problems and more prosocial behaviour. The study identifies various strengths and weaknesses of the programme and makes recommendations on how it could be organised more effectively in the classroom. The paper concludes that rather than taking CT as the default option for nurturing such values as student empowerment, inclusion and equity, there is a need for further rigorous studies on the impact of CT not only on students' social and emotional learning and behaviour but also on the classroom relationships and climate.
\end{abstract}

Keywords: circle time; primary school; social and emotional learning; behaviour; whole school approach

\section{Introduction}

Circle time (CT) is one of the most widely used universal interventions in the promotion of social and emotional learning in schools. In CT, children are encouraged to develop their social and emotional learning in a safe and caring environment through a child-centred and child-directed approach. CT provides a safe base where children can learn and practice social and emotional learning skills such as listening, expressing oneself, respecting others and problems solving within a caring, inclusive and democratic environment (Mosley, 2009). As the teacher takes a more facilitative role, students take a more active role in their learning within a structure facilitating and encouraging respect for one another, listening to each other, appreciating each other's views and perspectives, and collaborative problem solving. Learning is experiential, making use of such strategies as games, role plays, small group work, singing and physical activities. In such an environment, students do not only learn targeted specific skills, but the process itself is a powerful social and emotional learning experience.

\footnotetext{
*Corresponding author. Email: carmel.cefai@um.edu.mt
} 
There is a paucity of rigorous studies on the effectiveness of CT in schools (Cooper \& Jacobs, 2011; Lown, 2002; Mosley, 2009), while in some instances it may also lead to undesirable effects, such as serving as a medium for behaviour control, particularly with untrained teachers (Taylor, 2003; Watson, Emery, \& Bayliss, 2012). At a more general level, there is an ongoing debate on the 'rise of therapeutic education', promoted by such initiatives as SEAL in the UK, CASEL in the USA and KidsMatter in Australia. Concerns have been expressed about the potential labelling and stigmatising of vulnerable children through the introduction of social and emotional learning programmes, particularly programmes targeting specific groups of children (Ecclestone \& Hayes, 2009; Watson et al., 2012). It is also argued that education is not about mental health and well-being, and that teachers are educators and not surrogate psychologists or mental health workers (Craig, 2009). This is a particularly salient point in contexts where teachers face increasing pressure to ensure ever higher levels of pupil academic performance. Social and emotional learning, however, does not equate with mental health difficulties or with turning schools from learning communities into therapeutic centres (Ecclestone \& Hayes, 2009). The traditional deficit discourse may have hijacked the idea of what social and emotional learning in school is about, namely promoting well-being and maximising growth and potential for all children, including those facing risks in their development (Cefai \& Cavioni, 2013). CT is a universal intervention seeking to promote social and emotional learning as well as academic learning amongst all students in the classroom, with the teacher assuming the dual role of effective and caring educator.

Another issue with social and emotional learning is that it may detract from academic learning and lead to lower academic achievement (Benninga, Berkowitz, Kuehn, $\&$ Smith, 2006). The evidence shows, however, that social and emotional processes are at the heart of teaching and learning, providing a foundation upon which effective learning can be built and socio-emotional competence developed. They enable pupils to regulate their emotions, cope better with classroom demands and frustration, solve problems more effectively and relate better and work more collaboratively with others (Durlak, Weissberg, Dymnicki, Taylor, \& Schellinger, 2011; Greenberg, 2010; Greenberg \& Rhoades, 2008). A dual focus on academic and social-emotional learning promotes academic achievement, engagement, positive behaviour and healthy relationships (Dix, Slee, Lawson, \& Keeves, 2012; Durlak et al., 2011; Payton et al., 2008) and prevents the development of internalised and externalised problems (Battistisch et al., 2004; Blank et al., 2009; Waddell, Peters, Hua, \& McEwan, 2007).

Despite the lack of rigorous studies on the effectiveness of CT in schools, there are promising indications about the usefulness of CT from a number of small-scale projects and studies. Mosley (2009) reports on the evaluation of a CT project with 300 children in 16 primary schools in Ireland, mentioning a number of positive academic and behaviour outcomes, including improved concentration, listening and motivation, enhanced communication and collaboration, higher self-esteem and better behaviour. Mosley (2009) refers to two unpublished studies exploring the views of the Heads of primary school on CT in the UK by Dawson and McNess (1997) and Tew (1999) respectively; in both studies, the Heads reported that CT had a positive impact on the students such as enhanced self-esteem, and increased social skills and communication. In a study with over 500 primary school children in the UK, Miller and Moran (2007) reported that CT helped to create a climate where pupils felt valued and respected contributing to enhanced self-worth. In another study with eight schools in one local educational authority in the UK, Lown (2002) found that both teachers and pupils were positive 
about CT, reporting improvements in pupils' emotional literacy and social skills; teachers also said it helped them to understand their pupils and the difficulties they were facing. In a study with five primary school classrooms in Ireland, Collins (2011) reported that classroom relationships and climate improved as teachers sought to to enhance the children's confidence and self-esteem, develop their social and emotional learning, and ensure all children have a voice in the classroom.

Another study with 20 early years groups in the UK reported positive impact on both learning and behaviour goals in preschool (Wood, 2001). A number of studies in secondary schools found similar positive effects for secondary school students, including enhanced self and social awareness and more positive attitudes towards learning (e.g. Aguis, 2011; Hennessey, 2007; Kulchy, 2009; Tew, 1998). Other studies which made use of a multi-strategy approach, including CT, similarly reported improvements in emotional literacy and social skills such as listening and speaking (Coppock, 2007; Doveston, 2007).

Of particular interest to this publication is a recent qualitative case study on a whole school approach to CT in a small Maltese primary school (Pace, 2012). The study examined the views of teachers, students and parents on the introduction of CT for a whole term with all the groups at the school. Six classes, from Year 1 to Year 6, participated in the study, with a student population of 150 children and 14 members of staff. Staff, students and parents viewed CT as a positive experience for the whole school community. They mentioned such benefits as better teacher-pupil relationships, positive classroom climate and various social, emotional and academic benefits for the students, including enhanced motivation and engagement in academic learning such as listening, speaking and problem solving, positive behaviour and social and emotional learning, such as listening skills, communication skills, self-esteem and sharing of experiences. The staff also mentioned that it helped them to maintain positive student behaviour at both whole school and classroom levels, and reported less challenging behaviour and bullying at the school and more compliance with school and classroom rules. The teachers argued however, that issues such as time constraints and a heavy loaded curriculum were potential barriers to the effective implementation of $\mathrm{CT}$ in their classroom. The study was based on participants' perceptions and underlined the need for more rigorous investigations.

The present study carried out a semi-randomised controlled trial study on the effectiveness of CT on primary school students' social and emotional competence, making use of both quantitative and qualitative data. Its objective is to examine the effectiveness of CT by the classroom teacher in the students promoting social and emotional learning, identify the processes that facilitate and hinder its effectiveness, and explore the teachers' and students' experience of CT.

\section{Methodology}

A relatively large primary school in the centre of Malta was identified to participate in the pilot study. The school staff agreed to take part in the project led by the University of Malta. The project was spread across one scholastic year (2010-2011), with the first term dedicated to planning and identification of particpants, the second term training of classroom teachers in CT and the start of the implementation, and the third term the completion of the implmentation and evaluation. Originally it was planned to recruit two classes from each year (Year 1-Year 6) in a randomised control trial design, with the classes being randomly assigned to experimental or control groups. However, due to 
lack of volunteers and in consultation with the Head of School, a semi-RCT was considered more feasible. Year 6, the final year in the primary school, was not included as students were sitting for their final examinations and would be less likely to attend regularly during the last term of the scholastic year.

\section{Sample}

Five classroom teachers, one from each year (Year 1-Year 5) volunteered to implement $\mathrm{CT}$ in their classroom, while another corresponding five teachers agreed to participate as controls. The CT teachers received one session of training in the use of CT in the classroom by two qualified CT facilitators. The training session included a presentation on the benefits of CT in general, followed by a more detailed practical session on how to use CT in the classroom. Participants were provided with a resource pack which included detailed lessons plans to be used in the classroom. The topics included selfawareness and self-esteem, understanding and managing feelings, belonging, friendship and cooperation, and challenges and solutions. They were also offered mentoring during the implementation process, but no teacher made use of this service. Implementation by the teachers occured over a period of 10 weeks with one 30-45 min CT session per week.

\section{Instruments}

The Maltese version of the teacher's Strengths and Difficulties Questionnaire (SDQ) (Goodman, 1997) was used as a measure of the students' social, emotional and behaviour difficulties as well as prosocial behaviour. The SDQ is a brief questionnaire which has been used by many researchers as a screening tool to measure social, emotional and behaviour difficulties and prosocial behaviour, and identifies the prevalence of mental health difficulties among children and young people. Both the CT and the control teachers completed the SDQ teachers' version on a sample number of students in their classroom before the start of the CT programme and once again at the end of the programme. All 10 teachers completed the pre- and post-SDQ on a random sample of their children, namely every third name on the class register, with an average of seven students per class. In all, there were 74 students equally divided into the CT and control groups, 40 males and 34 females.

The CT teachers also completed a questionnaire at the end of the implementation, including open-ended questions on the practical aspects of the implementation, such as training, resources, support, logistics, fidelity and challenges faced. Another section dealt with the perceived student experience of CT and student outcomes in terms of the skills learnt. All five CT teachers completed the questionnaire.

The students attending Years 3-5 were also invited to complete a brief, child friendly questionnaire on their experience of CT at the end of the implementation. A quantitative section asked how much the students enjoyed and learnt from CT, and the specific skills they learnt, with five possible responses from 'Not at all' to 'A great deal'. The second section of the questionnaire asked open-ended questions on what they learned and what they liked and disliked during CT. Of the three classes, only two participated, namely Year 3 and Year 4, making up 43 students (20 males and 23 females). Parental consent was obtained for all the students who participated in the study.

The SDQ scores were analysed via Anova repeated measures while descriptive statistics and one way analysis of variance were used to anlayse the quantitative data from 
the students' questionnaires. The teachers' questionnaires and the second part of the students' questionnaires were anlaysed qualitatively, identifying the key themes emerging from the participants' responses.

\section{Findings}

\section{Pre- and post-SDQ scores for CT and control groups}

Table 1 shows a clear pattern in the means of the two groups, with a decrease of difficulties in the CT group from pre- to post-intervention, and a corresponding increase in scores in the control group. Significant interaction effects were found for the emotional symptoms subscale $\left[F(1,73)=4571, p=.036 ; \eta^{2}=.059\right]$, the peer relationships subscale $\left[F(1,73)=7553, p=.008 ; \eta^{2}=.094\right]$ and the total difficulty subscale $[F(1$, $\left.73)=6963, p=.010 ; \eta^{2}=.087\right]$, suggesting that the main impact of the programme was more on internalised difficulties, but with little apparent effect on externalised difficulties or prosocial behaviour (see Figures 1-3).

\section{CT teachers' questionnaire}

Four of the five teachers felt well prepared for the implementation, with two recommending more peer support and mentoring. This has clear implications for effectiveness as belief in one's competence and confidence is a key factor in programme effectiveness (Greenberg, 2010). All the teachers were actively engaged in the implementation of the programme in their classroom, and with one exception, they implemented the programme faithfully and regularly and found no particular difficulty in doing so, even if 'it was our first experience'. They also found the resources provided adequate, but some added some resources and activities themselves. This also helps the teachers to own more the programme and increase their self-efficacy as they feel they have more control. One of the teachers found difficulty in implementing the programme regularly as $\mathrm{s} / \mathrm{he}$ needed more support and more resources, and had problems in fitting the programme in the timetable.

One of the issues mentioned by the teachers was finding a regular time in the timetable for CT, with one teacher for instance, doing it instead of the creativity lesson. Clearly, it will be easier for the teachers to implement CT regularly and faithfully if there is a place for it in the regular curriculum. Another issue mentioned by the teachers was the number of children in their classroom and the physical space available. For instance, one teacher complained that 'with $20 \mathrm{kids}$, each session took much longer than planned', while another said that 'because I had a big number of children (25), some of them felt frustrated waiting for their turn to finish a statement'. Having adequate space at the school for the organisation of CT is a key factor in the successful implementation of CT. Teachers may also need to use particular strategies when they have large groups, such as 25 , such as using smaller group work and recruiting the support of the LSA when one is present in the classroom.

When asked what sort of assessment they used when implementing CT, only one teacher used the evaluation sheet provided with the guidebook, while another two observed students' behaviour and engagement during the sessions. One teacher underlined the need for monitoring and mentoring the teacher in this process.

All the teachers wrote that they reinforced the learnt skills during other lessons and classroom activities, making use of different strategies: 'Especially when things came 


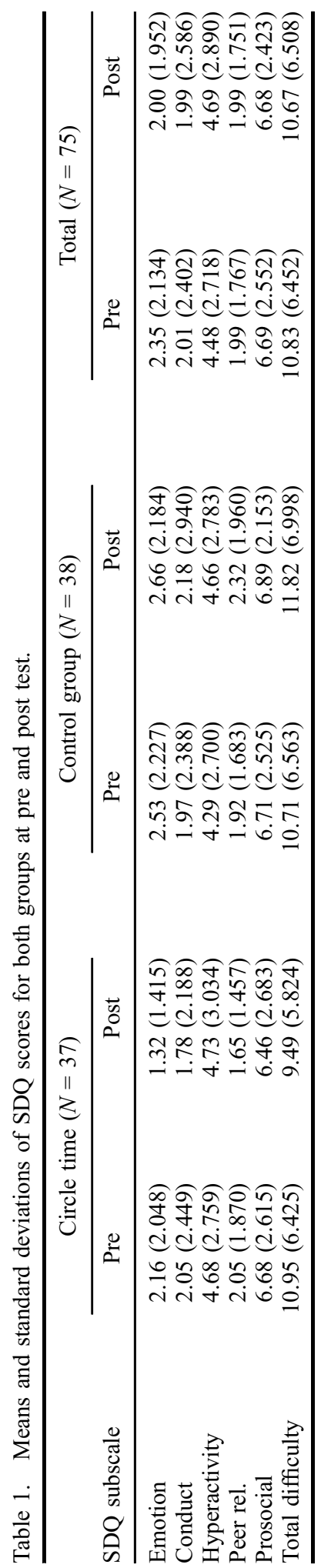




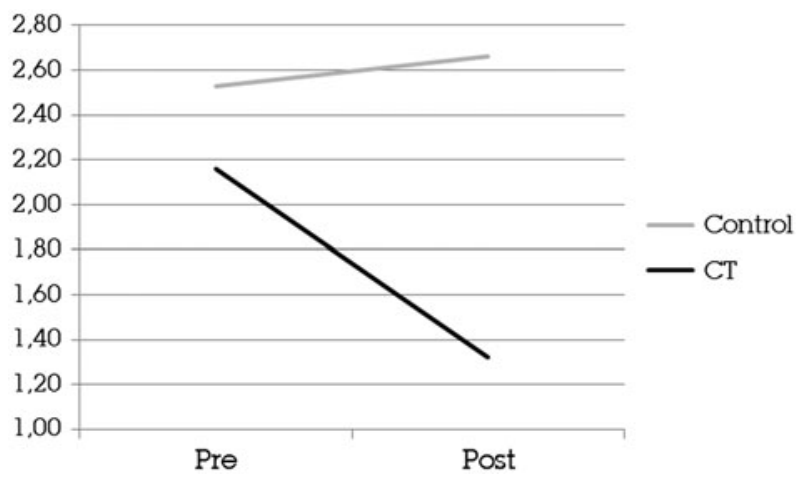

Figure 1. Interaction effect for emotional symptoms subscale.

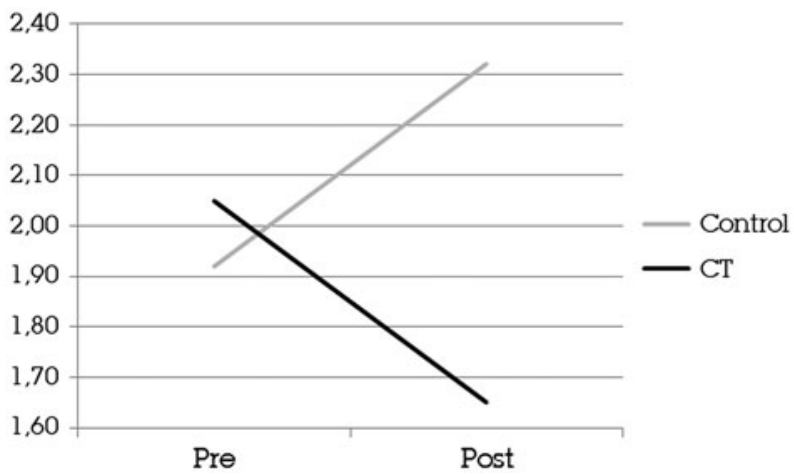

Figure 2. Interaction effect for peer relations subscale.

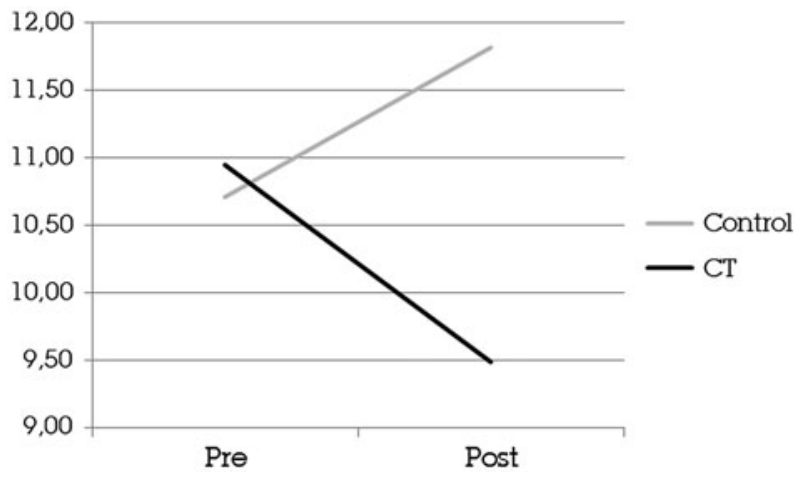

Figure 3. Interaction effect for total difficulty subscale.

up in the classroom where I could make the link', 'I used to discuss what we've learnt in the following days' and 'when a problem arises we ask what would Toby (soft toy) do or how he would feel'. One teacher used slogans from the 'balloon session' creating 
'a common language' with the students (e.g. 'Don't burst your balloon', 'Release a bit of air').

On the other hand, parents were not involved in the implementation. This is a limitation for CT effectiveness, because skills learnt at home could not be reinforced at home. Teachers mentioned the relatively short period of the implementation, but again this underlined the need for monitoring and mentoring during the implementation.

All the teachers believed that CT was an enjoyable learning experience and students were highly engaged in the sessions: 'they enjoyed every CT session'; 'they loved it!' The activities that worked really well included visualisation, calming down, energisers and group work. When asked what skills the students learned, listening skills was the main outcome according to most of the teachers; other skills mentioned include teamwork and better peer relationships, and improved attention and communication. In terms of overall outcome, the teachers suggest that in general CT impacted students' behaviour but had little impact on their academic achievement.

When asked whether they will be willing to do CT again next scholastic year, all the teachers expressed interest in doing so and saw it as an important area in the primary school curriculum. They made various suggestions on how it could be organised in a more effective way, such as having more songs, visualisation exercises, drama, video clips and energisers, as well as more training, adequate space and more promotion of CT at whole school level.

\section{Students' questionnaires}

\section{Quantitative data}

The vast majority of the students enjoyed CT (Figure 4), would like to see it again (Figure 5), and believed that they had learnt a great deal during CT (Figure 6). When asked about the specific skills they learnt during CT, (Table 2), students' answers suggest that they learned all the mentioned skills quite well, without distinguishing between one skill or set of skills and another. There was no significant difference between the eight skills nor any significant gender differences.

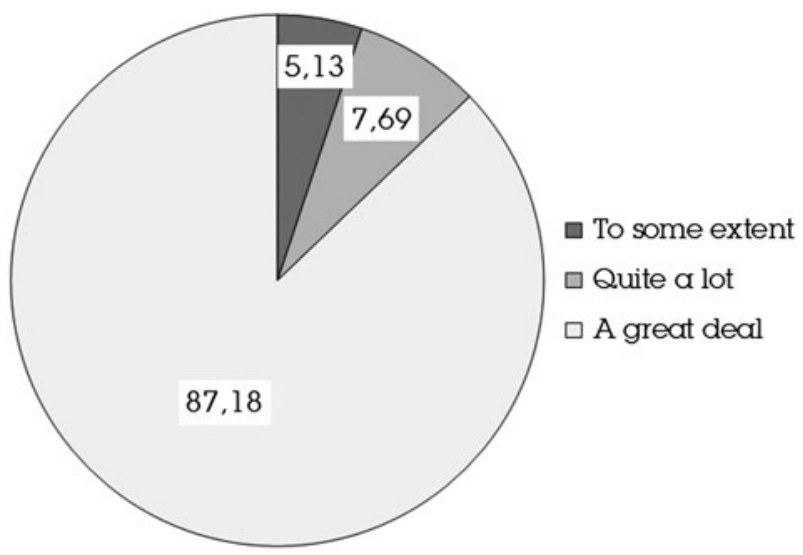

Figure 4. How much did you enjoy CT?

Note: No students ticked 'Not at all' or 'Only a little'. 


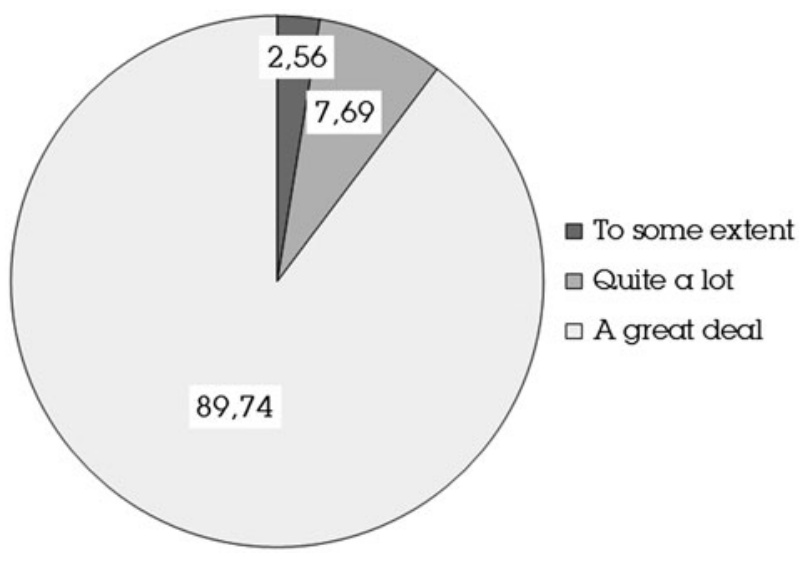

Figure 5. Do you wish to do CT again?

Note: No students ticked 'Not at all' or 'Only a little'.

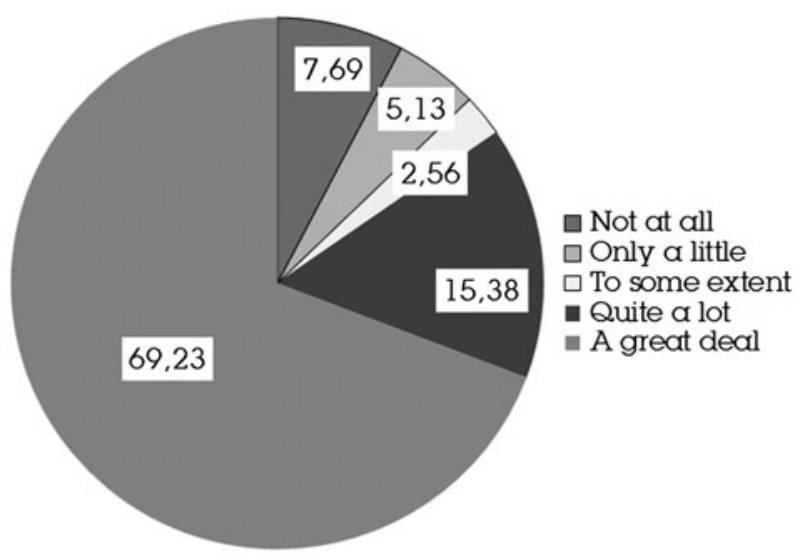

Figure 6. How much have you learnt during CT?

Table 2. Skills learned during CT $(N=39)$.

\begin{tabular}{llc}
\hline & Mean & $\begin{array}{c}\text { Std. } \\
\text { deviation }\end{array}$ \\
\hline Behave better in class & 3.49 & 1.144 \\
Understand myself better & 3.44 & 1.021 \\
Express myself better & 3.64 & .843 \\
Control my emotions & 3.51 & 1.121 \\
better & & \\
Make more friends & 3.69 & .950 \\
Understand peers better & 3.62 & .935 \\
Make good decisions & 3.64 & .707 \\
Solve problems better & 3.51 & 1.144 \\
\hline
\end{tabular}




\section{Qualitative data}

When asked what they liked in CT, most of the students mentioned practical activities such games (most liked activity), followed by singing and movement activities such as dancing, running or sports. These are also the things they would like to see more in CT. When asked what they did not like, most students mentioned peers' misbehaviour such as fighting, talking out of turn and interrupting others. The most important set of skills learnt concern social awareness and management: 'how to make friends', 'how to know peers', followed by listening to others, playing together without fighting and helping peers. This is followed by self-awareness and self-management skills, such as 'how to behave', 'how to wait', 'how to show hands', 'saying thanks' and 'know what happened'.

\section{Discussion}

The overall conclusion from the data is that CT contributed to students' social and emotional learning and to reduced social, emotional and behaviour problems. CT students showed less internalised problems and total difficulty scores at post-test when compared to their peers in the control group. There was no signficant difference, however, in externalised behaviour problems or in prosocial behaviour. One possible explanation could be that while the process of $\mathrm{CT}$ itself made children feel safer in thier classroom (hence less internalised difficulties) and helped them to work and relate better together, a longer intervervention was needed to reduce externalised behaviour problems and promote more prosocial behaviour. The data from the teachers' interviews, however, suggest that CT had a positive impact on the students' social and learning behaviours, such as listening, collaboration, better relationships with peers and attention. Similarly, the great majority of the students said they had learned a lot during CT, such as better peer relationships, making friends, improved behaviour and emotional regulation. Their responses suggested that their learning was spread across all the areas of self- and social awarness and management. These findings, however, need to be treated with caution, first as teachers' perceptions on the benefits of CT may not provide an accurate picture of the actual impact of CT on their own (Collins, 2011) and secondly because the students' responses could have been somewhat biased due to social desirability (Leach \& Lewis, 2013).

An interesting observation is that CT could be particularly helpful to reduce the difficulties of students with social, emotional and behaviour difficulites (SEBD). Both the SDQ results and the teachers' interviews seem to suggest that there was an improvement in student behaviour, with the SDQ underlining a reduction in internalised problems, and the qualitative data both in internalised and exteranlised probolems. This may indicate that $\mathrm{CT}$ as a universal programme may be particulalry effective for students with SEBD, hence underlying the need for inclusive universal interventions for students with SEBD besides targeted interventions (Greenberg, 2010). This is only a tentative conclusion but we believe it warrants further investigation (cf. Lee \& Wright, 2001).

The great majority of the students enjoyed CT and would like to have in it their curriculum; the teachers also confirmed that the students highly enjoyed the CT sessions (cf. Aguis, 2011; Camilleri, Caruana, Falzon, \& Muscat, 2012; Collins, 2011; Lown, 2002; Pace, 2012). The teachers themselves found CT a useful and meaningful experience and would like to do it again next year (cf. Lown, 2002). When asked what aspects worked well, both teachers and students underlined the experiential, practical 
and enjoyable aspect of the sessions, such as energisers, visualisation, games, singing and play. This resonates with the students in Pace's study (2012) who menioned such activities as the use of the speaking object, starter sentences, changing places, games and relaxation exercises as being key process in CT. The teachers mentioned that CT also helped in the classroom climate and in the learning proces, and they applied CT skills during the other areas of the curriculum.

When asked what did not work or could have worked better, students mentioned peers' misebahviour during CT, such as peers not following rules or fighting. This suggests that students were not yet used to $\mathrm{CT}$, and it may have taken some time for them to get used to, and follow, CT rules, such as waiting for their turn and talk only when they have the speaking object. The indications from the other data, however, such as the SDQ (less emotional problems and less peer relationship difficulties) and qualitative data from both the teachers and the students themselves did not suggest that students felt unsafe during CT. The students' answers, however, do raise concern that if not facilitated well, CT may create a climate conducive to bullying and behaviour problems in the classroom (Leach \& Lewis, 2013).

Teachers, on the other hand, mentioned more structural and organisational issues such as lack of time, lack of space and large number of students in class. On the one hand, teachers saw CT as a useful and worthwile initiative, but on the other, they expressed the need for more support in its planning and implementation. Having a place on the timetable, being promoted at the whole school level, involving the parents and providing classroom teachers with adequate training, mentoring and resources are some of the factors that would ensure that CT would be more likely to make an impact on the school community. The difficulties and challenges faced by the Maltese teachers resonate with those identified in other local and international research (Collins, 2011; Cremin, 2002; Lown, 2002; Pace, 2012). Cremin (2012) mentions such challenges as lack of time due to crowded curriculum, lack of adequate training and rescources, lack of belief in students' ability to take charge of their learning and lack of a whole school approach in the use of CT. The Maltese teachers in Pace's (2012) study similarly mentioned lack of time and overcrowded curriculum as being the main problems which may compromise the effective implementation of CT.

The main complaint of the teachers was the lack of time and overloaded curriculum. Such concerns may reflect the lack of value in SEL by educational systems when compared to academic learning, and the concern that SEL will take precious time away from academic learning. Yet, there is evidence that SEL contributes to academic motivation and engagement, enhancing skills essential for learning such listening, concentration, speaking and problem solving, as well as improves academic learning (Durlak et al., 2011; Payton et al., 2008). In order for CT to be effective, it thus needs to have a firm base in the curriculum with a specific regular slot in the classroom timetable. There needs to be also more awareness on the importance of SEL and CT at the whole school, with the whole school community being on board before CT is implemented at the school (Mosley, 2000). The staff's, students' and parents' motivation and readiness to embark on this initiative is crucial if CT is to become a meaningful and successful intervention (Cremin, 2002; Mosley, 2009). Moroever, CT needs to be embedded within a whole school supportive and caring climate, with the values being nurtured in the classroom resonating with those promoted at the whole school level (Cooper \& Jacobs, 2011). At the same time, however, schools needs to be clear on what CT is really about, namely that rather than providing therapy or counselling (Ecclestone \& Hayes, 2009), it 
is about social and emotional learning and problem solving within a caring classroom learning process (Mosley, 2009).

Another clear implication from the study is that the whole school staff will need adequate training in the design, implementation, monitoring and evaluation of the CT programme. Untrained teachers may engage in practices which go against the humanistic principles underlying CT, such as pupil empowerment, democracy, equity and unconditional positive regard (Doveston, 2007; Taylor, 2003). Staff will need to be convinced, for instance, of student empowerment, if they are to engage in good practice with student-directed learning (Cefai \& Cooper, 2010; Cremin, 2002; Leach \& Lewis, 2013). During CT, staff also need to be prepared to take a less directive and more facilitative role than in traditional teaching. The issue of adult power and children empowerment is one of the main issues in CT (Collins, 2011; Leach \& Lewis, 2013) and we will return to the conclusion.

Staff also need to be directly involved in collaborative planning of the programme and resource development, so that they will organise $\mathrm{CT}$ in a way that addresses the particular needs of their students and school community while owning the initiative themselves (Cremin, 2002; Pace, 2012). The staff may make use of CT themselves during the planning. This would boost their competence and consequently enhance their confidence in doing CT. They would need, however, adequate resources and support in the process, participating in a community of practice which includes monitoring, peer mentoring and support from specialist teachers. Taylor (2003), for instance, found that lack of monitoring led to some staff not respecting basic ground rules in $\mathrm{CT}$, such as non-judgmental positive regard and equity.

The teachers in the study were provided with an assessment sheet as part of the resource pack but most of them did not make use of it. It could be the teachers did not see CT as a area that needs to be assessed (Collins, 2011). Assessment is a crucial part of the learning process, but it needs to avoid the trappings of the traditional academic achievement assessment. CT assessment will be formative and developmental, with feedback from both the teachers and the children themselves on the competencies being learnt. It needs to be teacher-friendly, namely without burdening the teachers with further unnecessary paperwork and checklists, as well as student friendly, such as making use of illuminative techiques.

The parents were not involved in this study, but parental involvement will not only support the learning taking place during $\mathrm{CT}$ at the school but reinforce the development of the skills being learnt with further practice at home. CT may thus include take-home tasks which students would do with their family. Pace (2012) reported that the parents were highly appreciative of CT and saw it as an important part of their children's education, with one parent even suggesting CT sessions for the parents themselves.

CT needs to take into consideration, and address the needs, of students with individual educational needs. Cooper and Jacobs (2011) argue that students with autism and ADHD may not benefit from a traditonal CT without due modifications and support. Teachers in this study did not report any difficulties in engaging students with individual educational needs during CT while Pace (2012) reported that one group had a student with autism who participated actively during CT. Lee and Wright (2001) found CT promoted self- and social awareness and social skills such as listening amongst students with social, emotional and behaviour difficulties. The classroom teacher and the Learning Support Assistant, however, would need to work collaboratively together to ensure the maximum benefits of CT for such students (cf. Lown, 2002; Miller \& Moran, 
2007). In some cases, additional support in terms of smaller circles of support may also be indicated (Mosley, 2009).

The students greatly enjoyed CT, but the things they liked most have more to do with the process of learning during $\mathrm{CT}$, than with the actual content itself. This has clear implications for the overall teaching and learning processes, putting the onus on the classroom teachers to organise learning around students' needs and interests. Active participation, practical activities, games, songs, physical activity and small group work could be organised in any content area of the curriculum. CT may thus serve as a useful medium of instruction for the classroom teacher, not only for social and emotional learning but for the other areas of the curriculum as well. Learning as fun addresses one of children's basic psychological needs, namely the need for fun, adventure and enjoyable experiences, and feeds into their other basic needs, namely competence, autonomy and relatedness (Deci \& Ryan, 2000).

\section{Conclusion}

This was a small-scale study in one particular school and care needs to taken about making generalisations across schools and contexts. The CT programme itself was restricted to just one school term, with only some members of staff participating; moreover, those participating had volunteered to do so, with possible implications on the findings and conclusions of the study. Longer term, whole school intiatives are more likley to have an impact (Cooper \& Jacobs, 2011; Lown, 2002; Miller \& Moran, 2007). The monitoring of the programme was also limited, with some of the teachers asking for more support. The parents themselves were not involved in the study nor in the programme evaluation. Only two out of five groups of students participated in the study; use of illuminative techniques with the early years students could be used to capture their experiences as well. The small numbers also did not allow for examination of mean differences between one year group and another.

In both parts of the students' questionnaire, the responses are skewed with the likelihood that the students may have completed the questionnaire as a whole group with the class teacher. Although the questionnaires were completed and returned anonymously, there is the possibility that the students, or some of them, discussed the questions with their peers, and also that they wrote those answers they believed were expected by their teachers. Although this study sought to capture pupils' experience of CT through both quantitative and qualitative questions, the potentially biased answers may throw some doubt on the authenticity of such responses, and underline the need for more reliable and child-friendly methods of exploring children's real thoughts and feelings. In a small-scale study on children's experiences during CT, Leach and Lewis (2013) postulate that rather than serving as a vehicle for student voice and empowerment, CT may actually operate as another medium for maintaining adult control and power in the classroom. During CT, children are encouraged to open up and reveal personal issues and problems, and if issues of confidentiality and participation are not handled properly, CT may lead to a sense of insecurity and exposure and potential bullying. The authors underline the need for more rigorous research to capture the real lived experience of children during CT and the impact of such experiences on their psychological wellbeing.

$\mathrm{CT}$ is deemed to be a useful tool for schools in their effort to foster empowerment, inclusion, equity, democracy, agency as well as social and emotional and academic learning, amongst their students. It seeks to create a safe and caring classroom climate 
which promotes such values as sharing, supporting one another, listening and respecting each other's opinions, and enjoying and appreciating each other's company. It is also a time for fun and enjoyment during learning. There does not appear to be enough robust evidence, however, to substantiate such claims unequivocally, particularly that by default CT will operate as a medium for student empowerment, inclusion and equity (Collins, 2011; Cooper \& Jacobs, 2011; Leach \& Lewis, 2013; May, 2005). There is also the danger that if not handled well by the teacher, CT may inadvertently lead to undesirable outcomes such as isolation and bullying. These issues call for further rigorous scientific studies on the impact of CT not only on students' social and emotional learning and behaviour but also on the classroom relationships and climate. Such evidence would also serve to address the current challenges posed by the anti-therapeutic education movement on one hand and the raising academic standards in education (cf. OECD PISA) on the other.

\section{References}

Aguis, L. (2011). Developing emotional literacy with secondary school girls with social, emotional and behavioural difficulties (Unpublished masters dissertation). Faculty of Education, University of Malta, Malta.

Battistich, V., Schaps, E., \& Wilson, N. (2004). Effects of an elementary school intervention on students" "connectedness" to school and social adjustment during middle school. Journal of Primary Prevention, 24, 243-262.

Benninga, J. S., Berkowitz, M. W., Kuehn, P., \& Smith, K. (2006). Character and academics: What good schools do. Phi Delta Kappan, 87, 448-452.

Blank, L., Baxter, S., Goyder, L., Guillaume, L., Wilkinson, A., Hummel, S., \& Chilcott, J. (2009). Systematic review of the effectiveness of universal interventions which aim to promote emotional and social wellbeing in secondary schools. London: National Institute for Clinical Excellence.

Camilleri, S., Caruana, A., Falzon, R., \& Muscat, M. (2012). The promotion of emotional literacy through personal and social development: the Maltese experience. Pastoral Care in Education, 30, $19-37$.

Cefai, C., \& Cavioni, V. (2013). Social and emotional education in primary school. Integrating theory and research into practice. New York, NY: Springer.

Cefai, C., \& Cooper, P. (2010). Students without voices: The unheard accounts of students with social, emotional and behaviour difficulties. European Journal of Special Educational Needs, $25,183-198$.

Collins, B. (2011). Empowering children through Circle Time: An illumination of practice (Unpublished education doctorate dissertation). Faculty of Social Sciences, National University of Ireland, Maynooth.

Cooper, P., \& Jacobs, B. (2011). Evidence of best practice models and outcomes in the education of children with emotional disturbance/behavioural difficulties. Meath: National Council of Special Education.

Coppock, V. (2007). It's good to talk! A multidimensional qualitative study of the effectiveness of emotional literacy work in schools. Children \& Society, 21, 405-419.

Craig, C. (2009). Well-being in schools: The curious case of the tail wagging the dog. Glasgow: Centre for Confidence and Well-being.

Cremin, H. (2002). CircleTime: Why it doesn't always work. Journal of National Primary Trust, $30,23-29$.

Dawson, N. \& McNess, E. (1997). A report on the use of circle time in Wiltshire primary school. Unpublished report commissioned by Wiltshire Local Educational Authority.

Deci, E. L., \& Ryan, R. M. (2000). The 'what' and 'why' of goal pursuits: Human needs and the self-determination of behavior. Psychological Inquiry, 11, 227-268.

Dix, K. L., Slee, P. T., Lawson, M. J., \& Keeves, J. P. (2012). Implementation quality of wholeschool mental health promotion and students' academic performance. Child and Adolescent Mental Health, 17, 45-51. 
Doveston, M. (2007). Developing capacity for social and emotional growth: An action research project. Pastoral Care in Education, 25, 46-54.

Durlak, J. A., Weissberg, R. P., Dymnicki, A. B., Taylor, R. D., \& Schellinger, K. (2011). The impact of enhancing students' social and emotional learning: A meta-analysis of school-based universal interventions. Child Development, 82, 474-501.

Ecclestone, K., \& Hayes, D. (2009). Changing the subject: The educational implications of emotional well-being. Oxford Review of Education, 35, 371-389.

Goodman, R. (1997). The strengths and difficulties questionnaire: A research note. Journal of Child Psychiatry and Psychology, 38, 581-585.

Greenberg, M. T. (2010). School-based prevention: Current status and future challenges. Effective Education, 2, 27-52.

Greenberg, M. T., \& Rhoades, B. L. (2008). State-of-science review: Self regulation and executive function-What can teachers and schools do? London: Office of Science and Innovation Foresight Project: Mental Capital and Mental Wellbeing.

Hennessey, B. A. (2007). Promoting social competence in school-aged children: The effects of the open Circle Time program. Journal of School Psychology, 45, 349-360.

Kulchy, L. (2009). Establishing a circle time group based upon boundary setting. Retrieved August 1, 2013, from http://www.circle-time.co.uk/site/research/55

Leach, T., \& Lewis, E. (2013). 'Children's experiences during circle-time: A call for researchinformed debate. Pastoral Care in Education, 31, 43-52.

Lee, F., \& Wright, J. (2001). Developing an emotional awareness programme for pupils with moderate learning difficulties at durants school. Emotional \& Behavioural Difficulties, 6, 186-199.

Lown, J. (2002). Circle time: The perceptions of teachers and pupils. Educational Psychology in Practice, 18, 93-102.

May, H. (2005). Whose participation is it anyway? Examining the context of pupil participation in the UK. British Journal of Special Education, 32, 29-34.

Miller, D., \& Moran, T. (2007). Theory and practice in self-esteem enhancement: Circle-time and efficacy-based approaches-A controlled evaluation. Teachers \& Teaching, 13, 601-615.

Mosley, J. (2000). A report on the use of jenny mosley's whole school quality circle tim model in primary schools in the UK. Retrieved August 1, 2013, from http://www.circle-time.co.uk/site/ research $/ 6$

Mosley, J. (2009). Circle time and socio-emotional competence in children and young people. In C. Cefai \& P. Cooper (Eds.), Promoting emotional education: engaging children and young people with social, emotional and behavioural difficulties (pp. 119-130). London: Jessica Kingsley.

Pace, M. (2012). 'Let's get into a circle!': A study on Circle Time as a whole-school approach (Unpublished masters dissertation). Faculty of Education, University of Malta, Malta.

Payton, J., Weissberg, R. P., Durlak, J. A., Dymnicki, A. B., Taylor, R. D., Schellinger, K. B., \& Pachan, M. (2008). The positive impact of social and emotional learning for Kindergarten to eighth-grade students. Findings from three scientific reviews. Chicago, IL: CASEL.

Taylor, M. (2003). Going round in circles: implementing and learning from Circle Time. Slough: NFER.

Tew, M. (1998). Circle time: A much-neglected resource in secondary schools? Pastoral Care, 16, 24-26.

Tew, M.(1999). A report on the use of Jenny Mosley's whole school quality circle time model in primary schools in the UK. Unpublished report commissioned by All Round Success.

Waddell, C., Peters, R. V., Hua, R. M., \& McEwan, K. (2007). Preventing mental disorders in children: A systematic review to inform policy-making. Canadian Review of Public Health, 98, 166-173.

Watson, D., Emery, C., \& Bayliss, P. (2012). Children's social and emotional wellbeing in schools a critical perspective. Bristol: The Policy Press.

Wood, F. (2001). Can circle time in the foundation stage Support the early learning goals for personal, social and emotional development? (Unpublished dissertation). School of Education, University of Bristol, Bristol. 